\title{
Advances in Understanding and Harnessing the Molecular Regulatory Mechanisms of Vegetable Quality
}

\author{
Luyao Gao ${ }^{1,2,3}$, Ning Hao ${ }^{4,5}$, Tao Wu ${ }^{1,2,3 *}$ and Jiajian $\mathrm{Cao}^{1,2,3 *}$ \\ ${ }^{1}$ College of Horticulture, Hunan Agricultural University, Changsha, China, ${ }^{2}$ Engineering Research Center for Horticultural \\ Crop Germplasm Creation and New Variety Breeding, Ministry of Education, Changsha, China, ${ }^{3}$ Key Laboratory for \\ Vegetable Biology of Hunan Province, Changsha, China, ${ }^{4}$ College of Horticulture and Landscape Architecture, Northeast \\ Agricultural University, Harbin, China, ${ }^{5}$ Graduate School of Agricultural and Life Sciences, The University of Tokyo, Tokyo, \\ Japan
}

The quality of vegetables is facing new demands in terms of diversity and nutritional health. Given the improvements in living standards and the quality of consumed products, consumers are looking for vegetable products that maintain their nutrition, taste, and visual qualities. These requirements are directing scientists to focus on vegetable quality in breeding research. Thus, in recent years, research on vegetable quality has been widely carried out, and many applications have been developed via gene manipulation. In general, vegetable quality traits can be divided into three parts. First, commodity quality, which is most related to the commerciality of plants, refers to the appearance of the product. The second is flavor quality, which usually represents the texture and flavor of vegetables. Third, nutritional quality mainly refers to the contents of nutrients and health ingredients such as soluble solids (sugar), vitamin C, and minerals needed by humans. With biotechnological development, researchers can use gene manipulation technologies, such as molecular markers, transgenes and gene editing to improve the quality of vegetables. This review attempts to summarize recent studies on major vegetable crops species, with Brassicaceae, Solanaceae, and Cucurbitaceae as examples, to analyze the present situation of vegetable quality with the development of modern agriculture.

Keywords: gene manipulation, vegetables, quality, Brassicaceae, Solanaceae, Cucurbitaceae

\section{INTRODUCTION}

With the improvement of living standards, an increasing number of people are paying close attention to the nutritional components and taste of vegetables. On the market, high-quality vegetables, such as broccoli, which contains high glucoraphanin levels, and cucumbers, which have glossy peels, are popular with consumers (Jin et al., 2014; Zhang et al., 2021). With the development of society and the improvement of people's living standards, consumers not only seek vegetables to eat but also have a wide range of choices of vegetables, with the accompanying expectations that they are attractive, nutritionally rich, delicious, fresh, safe and environmentally friendly. Given the requirements for the quality of vegetables, researchers have focused their efforts on systematic studies about the nutritional value of vegetables. In general, vegetable quality includes sensory characteristics and biochemical properties, which can be divided into three aspects, i.e., appearance, texture, and flavor, whereas biochemical properties can be used in the analysis and evaluation of the nutritional value and safety of vegetable crop species (Aung and Chang, 2014; Liu et al., 2017; Bort et al., 2019; Zhao et al., 2019). 
The quality evaluation criteria of different vegetables and the regulatory mechanisms behind these traits are quite different (Figure 1). Therefore, summarizing the quality characteristics of different crop species is necessary to improve vegetable quality by gene manipulation. Currently, in addition to traditional radiation mutagenesis, chemical mutagenesis, and hybrid breeding methods, genetic manipulation is gradually being applied in the innovation of vegetable crop germplasm resources, but its specific application in quality improvement remains unclear. This paper summarizes the application of genetic manipulation to improve vegetable quality.

\section{QUALITY CHARACTERISTICS OF Brassicaceae}

Consumers often judge the quality of vegetable crops by their appearance. For example, consumers prefer densely colored cabbage leaves because they believe that the short light time and/or short growth cycle cause(s) the color of cabbage to be light, which leads to a relatively low nutritional quality (Amagai et al., 2021). Moreover, different consumers make various choices regarding vegetable quality due to their different needs or preferences. For instance, someone may prefer loosetype cabbage because they find its leaves to be crisp and sweet when chewing. Conversely, firm cabbage has a higher plant fiber content and is softer and more flexible. Therefore, germplasm resources of different qualities must be created to align with various consumer expectations.

\section{Commodity Quality of Brassicaceae}

Commodity quality refers to morphological characteristics that can be evaluated by appearance, including plant type, plant height, leaf size, leaf color, petiole characteristics, handle color, and handle shape (Cox et al., 2003; Cheng et al., 2009; Olfati et al., 2010; Kim et al., 2020). There are regional differences in the requirements for the quality of vegetables due to different eating and consumption habits. Many kinds of large-leaf Chinese cabbage can be found in northeast China, while small-leaf Chinese cabbage is most popular in southern China. For Brassicaceae, leaves are the most important organ because they are often edible or are involved in nutrient accumulation, and leaf size determines product yields. Current evidence shows that the Brassicaceae leaf area is connected with phytohormones. The transcription factor AINTEGUMENTA (ANT), which encodes the APETALA2/ETHYLENE RESPONSE FACTOR $(A P 2 / E R F)$ family, responds to auxin and regulates downstream gene expression related to organogenesis and cell proliferation, indicating that $A N T$ promotes leaf growth by regulating cell division (Klucher et al., 1996; Note-Wilson et al., 2010; Ding et al., 2018; Karamat et al., 2021). Three ANT and six ANT-like (BrAIL) genes were identified in Chinese cabbage; the expression of the BrANT gene and three BrAIL genes increased with auxin treatment, and the leaf size increased (Ding et al., 2018). ETHYLENE RESPONSE FACTORS (ERFs) encode AP2/ERF superfamily transcription factors, which are the central components of the ethylene signaling pathway (Muller and
Munne-Bosch, 2015). Overexpression of BrERF4 in Arabidopsis thaliana can reduce leaf size by inhibiting cell expansion. For BrERF4 overexpression, two EXPANSIN (EXP) genes, AtEXPA5 and AtEXPA10, are downregulated in A. thaliana (Park et al., 2012). Thus, ethylene can effectively regulate Brassicaceae leaf size. In addition to leaf size, leaf shape can affect consumer choice; for example, some consumers prefer split-leaf Chinese cabbage, but others prefer round leaves. LOST MERISTEM2 (BrLOM2) may be the main factor regulating the phenotype of split leaves. A comparison of the round-leaf Chinese cabbage with split-leaf near isogenic lines shows that the expression of BrLOM2 in split leaves increases synchronously with the number of leaf edge cracks (Shu-juan et al., 2016). Moreover, the plant surface is crucial in determining vegetable quality, including brightness and color. The wax content in Brassicaceae is the main factor controlling brightness, and it also affects stress defense. One principal component analysis of different waxy materials showed that the expression of the LIPID TRANSFER PROTEINS (LTP2) gene is higher in the least waxy lines and that of the ECERIFERUM3 (CER3) gene is more highly expressed in the most waxy lines in Brassica oleracea var. capitata, indicating that LTP2 and CER3 may be related to the wax content (Laila et al., 2017). Scanning electron microscopy and gas chromatographymass spectrometry (GC-MS) revealed that the wax content of the CRISPR-BoCER1 plant " $C W 1-3$ " is significantly lower than that of the wild type, proving that BoCER 1 is crucial in the biosynthesis of cabbage epidermal wax (Cao et al., 2021). In addition to affecting glossiness, wax-related genes play an important role in defense against adverse stresses and are worthy of further exploration. In terms of color, for example, purple leaf Brassicaceae varieties are popular on the market. Given the different colors of vegetables, the contents of pigments also varies. Li et al. (2019) found that the relative expression of BASIC HELIX-LOOP-HELIX49 (bHLH49) in stalks and young leaves of Zicaitai "Xianghongtai 01 " is significantly higher than that in Caitai "Yinong50D," indicating that bHLH49 affects the color formation of Zicaitai. These studies on the appearance of Brassicaceae will help enrich commodity quality and provide consumers with more choices.

\section{Flavor Quality of Brassicaceae}

Brassicaceae flavor quality includes sweetness, crispness, softness, juiciness and the lack of undesirable smells. In particular, the leaves and petioles tend to be soft, the odor should be fresh and fragrant, and the material should be tender and strong (Wright et al., 2006). Moreover, high oxygen atmospheric packaging (> $70 \mathrm{kPa}, \mathrm{HOAP}$ ) can maintain vegetable quality. HOAP affects the production of hydrogen peroxide $\left(\mathrm{H}_{2} \mathrm{O}_{2}\right)$, increases cabbage tissue firmness, and significantly reduces the contents of hemicellulose, cellulose, and lignin in the stem. Therefore, the decrease in the $\mathrm{H}_{2} \mathrm{O}_{2}$ signal in hemicellulose, cellulose, and lignin biosynthesis may be related to the differential accumulation of oxidative stress-related proteins that are induced by HOAP treatment (Wang et al., 2020). At present, studies about Brassicaceae flavor quality are limited, and the mechanism by which special flavors are formed has not yet been found. 


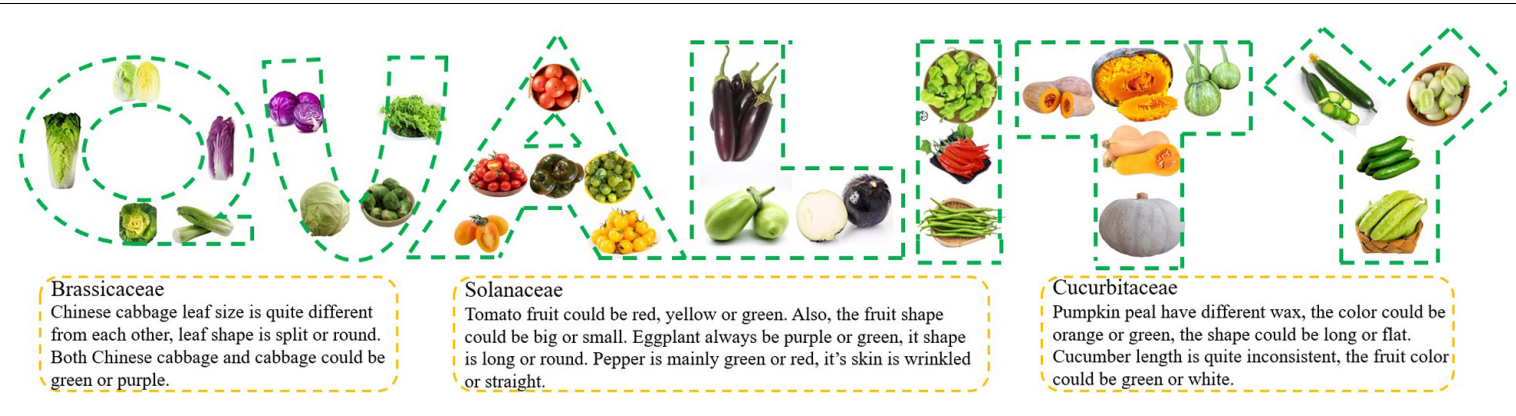

FIGURE 1 | Overview of the different vegetable commodity characteristics, with Brassicaceae, Solanaceae, and Cucurbitaceae as examples. Extensive research has been performed to optimize leaf size (e.g., split or round Chinese cabbages), leaf color (e.g., green or purple cabbages), fruit color (e.g., red, yellow or green tomatoes, purple or green eggplants, and orange or green pumpkins), fruit shape (e.g., big or small tomatoes, wrinkled or straight eggplants, and long or flat pumpkins), and fruit size (e.g., cucumbers of different lengths). Vegetables are usually optimized to meet consumer expectations for product quality, including appearance, taste, and texture.

\section{Nutritional Quality of Brassicaceae}

Nutritional quality refers to nutritional value, which is mainly determined by the contents of nutrients but is also affected by the contents of harmful components and pollutant residues. The nutritional quality of Brassicaceae requires high contents of flavonoids, L (+)-ascorbic acid (AsA), dry matter, soluble solids, and vitamins; a moderate content of crude fiber; a low content of nitrate; and absence of pollutant residues such as pesticides. The unique nutritional quality of Brassicaceae is attributed to flavonoids. Watercress is a special plant rich in flavonoids. Four important watercress varieties were compared with non-heading Chinese cabbage by ultrahigh-performance liquid chromatography-electrospray ionization-tandem mass spectrometry (UHPLC-ESI-MS/MS). A total of one hundred thirty-two flavonoid metabolites were detected: eight anthocyanins, two dihydroflavonoids, three dihydroflavonols, one flavonoid, twenty-two flavonoids, eleven flavonol carbon glycosides, eighty-two flavonols and three isoflavones. Marked differences in flavonoid metabolites were found in different samples, and all of them exhibited their own unique metabolites (Ma et al., 2021). The most important nutritional quality of Brassicaceae is the content of AsA, which can be regenerated from monodehydroascorbate and dehydroascorbate by MONODEHYDROASCORBATE REDUCTASE (MDHAR). Overexpression of MDHAR1 from non-heading Chinese cabbage reduces the AsA level and growth in transgenic tobacco (Ren et al., 2015). Additionally, there is a very significant negative correlation between the nitrate content and AsA content in leaf lettuce (Koyama et al., 2012). These results provide a reference for enhancing the nutritional quality of Brassicaceae crop species.

\section{QUALITY CHARACTERISTICS OF Solanaceae}

Given that people eat only the fruits of solanaceous crop species, the key to improving the quality of solanaceous crops is to focus on fruit quality. Consumers have different evaluation standards for the fruit quality of Solanaceae. For example, tomatoes with uniform color, thin skin, and no cracks are more popular than their counterparts. When the taste is sweet and sour, the quality of tomatoes is considered high. Similarly, uniform color and strong luster are important qualities for peppers. Plump and juicy peppers taste better and are more popular with consumers than their counterparts. Less spicy peppers with moderate aromas sell well in northern China. However, peppers with high levels of spiciness and strong scents are highly popular among consumers in southern China, such as Sichuan and Hunan Provinces. In addition, factors such as cooking techniques and geographical restrictions lead to different consumer needs, so many varieties of solanaceous crops exist on the market.

\section{Commodity Quality of Solanaceae}

Tomatoes, peppers, and eggplants are common Solanaceae vegetables and are important parts of our table dishes. Given that the main edible part of solanaceous crops is the fruit, fruit shape and color are important commodity qualities. For example, the best-selling tomato requires uniform coloring, bright color, small cracks in the apical pedicel, and no longitudinal or ring cracks (Yildiz and Baysal, 2007; Liu et al., 2020; Xue et al., 2020). Currently, most consumers prefer bright red or pink fruit colors, and a few prefer an orange fruit color, which varies with the changes in eating habits in different regions (Veerappan et al., 2016; Yang et al., 2019). Similar to Brassicaceae, pigments, such as chlorophyll, lutein, carotene, and anthocyanin, affect the color of tomatoes. The expression of the structural flavonoid genes is closely followed by MYB12, suggesting that MYB12 regulates the production of flavonoids in tomato fruit by activating the transcription of the genes encoding these pathway enzymes, and MYB12 is also reported to be suppressed in pink line tomatoes (Adato et al., 2009; Ballester et al., 2010). SlMYB12 mutation leads to premature termination of the amino acid sequence and structural changes, resulting in a colorless epidermis phenotype in tomato fruits (Veerappan et al., 2016). Compared with yellow tomatoes, ISOPENTENYL DIPHOSPHATE ISOMERASE 1 (IDI1) is a cytoplasmic enzyme involved in the biosynthesis of isoprenoids, 
including cholesterols, that inserts a single $\mathrm{T}$ base into exon 6 in apricot tomatoes, resulting in a decrease in carotenoid content and yellow pericarp (Nakamura et al., 2015; Shin et al., 2019; Chattopadhyay et al., 2021). Several genes and their mutant alleles related to carotenoid biosynthesis have been identified and characterized in tomato fruit. PHYTOENE SYNTHASE (PSY1), CAROTENOID ISOMERASE (CrTISO), LYCOPENE BETA CYCLASE (CYC-B), and LYCOPENE ECYCLASE ( $L C Y-E)$ mutations can affect the carotene content and change the color of the tomato epidermis, but the mechanisms of the formation of different colors remain unclear (Hwang et al., 2016; Yoo et al., 2017; Chen et al., 2019). For purple eggplant, pericarp color intensity is an important economic characteristic. Many factors are considered in assigning the final color intensity, one of which is the accumulation of anthocyanins and chlorophyll. Comparing two advanced purple eggplant lines, EP26 and EP28, with different pericarp color intensities, a higher anthocyanin content and lower chlorophyll content were observed in EP26, and deeper pericarp color intensity was observed at two developmental stages. In addition, comparative transcriptome analysis of EP26 and EP28 showed that 131 transcription factors, including those of the MYB, bHLH, WRKY and NO APICAL MERISTEM, Arabidopsis TRANSCRIPTION ACTIVATION FACTOR1/2, and CUP-SHAPED COTYLEDON (NAC) families, displayed dynamic changes, which may have been due to the changes in fruit pigment accumulation between EP26 and EP28 (Zhou et al., 2021). Although some genes related to Solanaceae fruit color have been clarified, the mechanism by which different colors are formed has yet to be elucidated. Further research on the molecular regulatory mechanism of color is necessary to create multicolor germplasm resources.

Tomato cracking generally occurs during fruit ripening and is affected by genetic or environmental factors such as fruit firmness, cuticle characteristics, abscisic acid (ABA), gibberellins (GAs), water, light and nutrients (Cox et al., 2003; Bargel and Neinhuis, 2005; Khadivi-Khub, 2015; Yang et al., 2016; Jiang et al., 2019). Cracking greatly reduces the edible value of tomatoes, and tomatoes with no cracks are highly popular on the market. One crack-resistance gene, $C r 3 a$, was found by mapping. The water content of cracked tomato fruit during the green ripening period was significantly higher than that of the Cr3a crack-resistant tomato. However, no significant difference in the thickness of the cuticle or the number of epidermal cells was found between these two kinds of tomatoes, and the mechanism remains unclear (Yu et al., 2020). In addition to these genetic or environmental factors, tomato cracking is related to the pectin content. POLYGALACTURONASE (PG) can degrade the pectin backbone, and EXPANSIN (EXP) is a non-enzymatic cell wall active protein. PG and EXP cooperatively disassemble wall polysaccharide networks and contribute to the softening of fruit. By suppressing SlPG and SlEXP1 expression in tomato fruit $(p g / \exp )$, the content of water-soluble pectin decreases in the pericarp, whereas the content of propectin increases. Although the cell wall and wax layer become thicker and the $p g / \exp$ fruit hardens, the rate of fruit cracking is reduced due to the firm protopectin (Jiang et al., 2019).
The texture of the fruit, especially the firmness, is the main quality of fresh tomatoes evaluated by consumers (Hongsoongnern and Chambers, 2008; Brashlyanova et al., 2014). Most consumers prefer hard tomatoes, which have better cooking characteristics. The factors affecting the firmness of tomatoes are epidermal toughness, pulp firmness and the internal structure of fruits (Chapman et al., 2012; Romero and Rose, 2019). FIRM SKIN 1 (FIS1) encodes a GA2-oxidase, and changes in the level of GAs can induce parthenocarpic development and affect fruit maturity in tomatoes (Martinez-Bello et al., 2015; Li et al., 2019). Early termination of the FIS1 gene increases the biological activity of GA, the biosynthesis of thorny and waxy layers, and the shelf life and firmness of fruits in tomato (Li et al., 2020). These changes improve the firmness of tomato fruits, thereby increasing transportability and yielding more economic benefits.

\section{Flavor Quality of Solanaceae}

For tomato, the main factors affecting flavor quality are the contents of sugar and acid and the ratio of sugar to acid (Beckles, 2012). High sugar and low acid contents make the tomato taste light, whereas a low ratio of sugar to acid makes the tomato taste sour. When both are low, the fruit is tasteless. For good flavor, the fruit must have a high sugar content and high sugar:acid ratio. In recent years, given the obvious diversification of consumer groups, tomato fruits with increased acidity have been favored by special groups such as beverage lovers under the premise of a high sugar content. The cell wall CONVERTING ENZYME INHIBITOR 1 (SlCIF1) gene, which is involved in tomato glucose metabolism, activates the small HEAT SHOCK PROTEIN 17.7 (SlHSP17.7) gene to control the flavor of tomato. In SlHSP17.7RNA interference (RNAi) lines, the sweetness of tomato is significantly decreased by modulation of the contents of sucrose and fructose (Zhang et al., 2018).

Spicy taste is a unique flavor quality of pepper. Wholegenome sequencing and assembly of the hot pepper (Mexican landrace of Capsicum annuum cv. CM334) revealed fiftyfour CAPSAICINOID BIOSYNTHETIC GENES (CBGs) related to the spicy taste of pepper; $C B G s$ are specifically expressed in the placenta of pepper, but the mechanisms behind these genes are unclear (Kim et al., 2014). MYB31 is a transcription factor specifically expressed in pepper placenta. Transcription level analysis revealed that MYB31 is highly coexpressed with $C B G$. Further experiments revealed that MYB31 directly regulates ACYLTRANSFERASE 3(AT3), which exhibits developmentally regulated placenta-specific expression and participates in capsaicin biosynthesis by binding to MYB ciselements. Moreover, MYB31 directly regulates $C B G$ expression and participates in capsaicin biosynthesis (Zhu et al., 2019). Consumer preferences for pepper spiciness are affected by subjective factors, so breeders can select corresponding varieties depending on the preferences of local consumers.

\section{Nutritional Quality of Solanaceae}

The content of AsA is an important index of quality. MYOINOSITOL OXYGENASE (MIOX) is a critical enzyme in the plant AsA biosynthesis pathway. MIOX4 overexpression tomato lines show a significant increase in total ascorbate in 
leaves and red fruits compared to the control (Munir et al., 2020). After the knockout of ASCORBATE OXIDASE (AO) and mitochondrial ASCORBATE PEROXIDASE (mitAPX), the decreased $\mathrm{AO}$ enzyme activity and significantly improved AsA content in tomato fruit were observed to be correlated with $A O$ gene suppression, and the downregulated mitAPX expression and APX enzyme activity led to an increase in the content of AsA in tomato fruits compared with the wild type, indicating that $A O$ and APX can improve the content of AsA (Zhang et al., 2011a,b).

\section{QUALITY CHARACTERISTICS OF Cucurbitaceae}

The common Cucurbitaceae vegetable crops include cucumbers (Cucumis sativus L.) and pumpkins (Cucurbita moschata), and their morphological characteristics are quite different from each other. Cucumbers with a slender and uniform body are preferred for cooking and fresh eating in China. To make pickled cucumbers, Russians prefer short fruits. Moreover, some people believe that cucumbers with small and dense thorns are better, and those with large and sparse thorns do not have the unique flavor of cucumbers. However, other people like cucumber fruit without thorns and growths. For yellow or green pumpkin, people believe that the darker the pumpkin is, the greater the sweetness. Consumers also find that yellow pumpkin is suitable for steaming or cooking porridge to make various cakes, while green pumpkin is suitable for fried food. In addition to cucumbers and pumpkins, Cucurbitaceae vegetables such as melons and watermelons exist in various shapes and colors. Therefore, Cucurbitaceae crops of different qualities should be cultivated to meet the demands of consumers.

\section{Commodity Quality of Cucurbitaceae}

The main edible part of Cucurbitaceae crop species such as cucumber is the fruit. Together with tomato and other Solanaceae crops, pericarp color, pulp color, and fruit luster are also important commodity qualities of Cucurbitaceae vegetables (Zhang et al., 2019; Gebretsadik et al., 2021; Mashiane et al., 2021). Fruit length and wax powder are the unique commodity qualities of Cucurbitaceae crops and have long been the focus of research (Hu et al., 2011; Dou et al., 2018; Ding et al., 2020). For cucumbers, it is difficult to select for fruit firmness during breeding. Peterson et al. found that cucumber firmness was quantitatively inherited with sufficient additive effects, so environmental effects and polygenic heritability were obvious. Fruit length is important to Cucurbitaceae crops, especially cucumber. Similar to Brassicaceae, some key genes controlling cucumber fruit length have been identified that are related to plant hormones, especially auxin. Knockout of the FRUITFULL 1 (CsFUL1) gene results in further elongation of cucumber fruit, while the high expression of the CsFUL1 gene significantly shortens cucumber fruit. In addition, CsFUL1 inhibits the expression of the auxin transporters PIN-FORMED1 (PIN1) and PIN7, resulting in a decrease in auxin accumulation in fruit, thereby affecting the fruit length of cucumber (Jiang et al., 2015; Zhao et al., 2019). To clarify the effect of plant hormones on the length of cucumber fruit, researchers can adjust the morphology of high-quality cucumbers in the actual production process. Wax powder is one of the factors affecting the glossiness of fruit. The AtWAX2 homolog CsWAX2 in cucumber was cloned and found to be highly expressed in synthetic waxy epidermis. The ectopic expression of CsWAX2 in the Arabidopsis wax2 mutant can partially complement the bright stem phenotype (Wang et al., 2015). Additionally, grafting cucumber onto pumpkin rootstock is an effective way to produce glossy cucumber fruits. AtWIN1 is a regulator of wax biosynthesis that can activate the expression of wax biosynthesis genes such as CER1, CER2, and KCS1; when the expression is enhanced, the mutant Arabidopsis became glossier than the wild type (Broun et al., 2004). CsWIN1 and several key wax biosynthesis genes, including CsCER1, CsCER1-1, CsCER, 4,3-KETOACYLCoA SYNTHASE (CsKCS1) and the wax transport gene ATPBINDING CASSETTE (CSABC), are significantly upregulated in cucumber grafted onto pumpkin, so these genes are positively correlated with wax synthesis. More wax esters (C20 fatty acid composition) and fewer alkanes (C29 and C31) were deposited in the grafted cucumber pericarp, probably due to the high wax ester content and the high integration of small trichomes in the pericarp (Zhang et al., 2019). However, there are few studies on the glossiness of Cucurbitaceae, and the mechanism needs to be further clarified.

\section{Flavor Quality of Cucurbitaceae}

Using cucumber as an example, its flavor quality generally refers to its unique smell and taste (Shimomura et al., 2016). The bitterness of Cucurbitaceae is caused by cucurbitacin. The transcription factors BITTER LEAF $(B L)$ and BITTER FRUIT $(B T)$ can be used to regulate bitterness formation in leaves and fruits, respectively, by applying the integrative bioinformatics and molecular biology approaches described above. Researchers have identified four additional P450 genes (Csa3G698490, Csa3G903540, Csa3G903550, and Csa1G044890) that are coexpressed with the $B I$ cluster (Shang et al., 2014). In addition to bitterness, unique aromatic substances and some non-volatile substances have been reported in cucumber. Researchers used GC-MS to analyze eighty-five volatile chemicals, including thirty-six volatile terpenes in twenty-three different tissues of cucumber, and found that TERPENE SYNTHASE11 (TPS11)/TPS14, TPS01, and TPS15 are responsible for volatile terpenoid production in the roots, flowers, and fruit tissues of cucumber plants and can improve cucumber flavor (Wei et al., 2016). Many kinds of cucumber flavor substances have been identified, of which (E,Z)-2,6non-adienal (NDE) is an important commercial flavor. NDE has been found in various plant materials, but cucumbers are considered the best source of this flavor substance. NDE production is reduced by acidification, enhanced by linolenic acid, and unaffected by unsaturated fatty acids, $\mathrm{NaCl}$ or $\mathrm{CaCl}_{2}$ (Buscher and Buscher, 2001). Cucurbitacin is a unique substance of cucumbers. The mechanism of cucumber bitterness must be clarified to combine the non-bitterness characteristics with other excellent characteristics to cultivate high-quality cucumbers. 


\section{Nutritional Quality of Cucurbitaceae}

Nutritional quality mainly refers to the nutrition and health care ingredients needed by the human body. For cucumber, pumpkin and other Cucurbitaceae crops, AsA, soluble solids, soluble protein, soluble sugar and other traits are important for the measurement of nutritional quality (Ge et al., 2017; Gao et al., 2018; de Almeida et al., 2019; Buzigi et al., 2021). ASCORBATE OXIDASE is a copper-containing enzyme localized at the apoplast, where it catalyzes the oxidation of AsA to dehydroascorbic acid (DHA) via a monodehydroascorbic acid (MDHA) intermediate. Similar to solanaceous crops, AO can also affect the content of AsA in Cucurbitaceae crops. The reduction in $\mathrm{AO}$ activity increases the AsA content in melon (Cucumis melo L.) fruit, which is due to the oxidation of AsA and the expression of certain biosynthetic and recycling genes, such as CmAPX1, CmMDHAR, and CmDHAR (Chatzopoulou et al., 2020). Consequently, the ascorbate redox state is altered in the apoplast. Interestingly, transgenic melon, which suppresses $\mathrm{AO}$ expression, displays an increased ethylene production rate coinciding with elevated activity and gene expression levels of 1-aminocyclopropane-1-carboxylic acid (ACC) oxidase (ACO), which might contribute to early ripening; moreover, $\mathrm{AO}$ participates in the rapid fruit growth of Cucurbitaceae in vivo (Chatzopoulou et al., 2020). Sugars provide a strong, pleasant, sweet taste and deliver energy when ingested; appetite regulatory centers respond to the energy content of sugar, which has a major influence on human health (Anderson, 1995). Thus, studies on the soluble sugar content of vegetables are of great significance. Comparing two cultivated pumpkin lines with different sweetness, C. maxima inbred lines "98-2" and "312-2," the glucose content of " $312-1$ " decreased rapidly in the early stage of fruit development, which may have been related to the high expression of sucrose INVERTASE (INV) and HEXOKINASE $(H K)$ at this stage. In contrast, FRUCTOSE KINASE (FK), which is responsible for fructose metabolism, is differentially expressed at different stages of fruit development. These results suggest that $I N V, H K$, and $F K$ may serve important roles in promoting sucrose biosynthesis during pumpkin fruit development (Wang et al., 2020).

\section{COMPLEXITY OF VEGETABLE QUALITY REGULATION}

From the above, many studies on the genes related to the regulation of vegetable quality have been conducted, and genes that are highly conserved or belong to the same gene family in different varieties are likely to have close functional correlations (Figure 2). For example, MDHAR, the key enzyme in AsA synthesis, can catalyze the reduction of MDHA to AsA (Park et al., 2016). When MDHAR was silenced in different species, such as melon, acerola, and Chinese cabbage, the content of AsA decreased (Eltelib et al., 2011). Moreover, SUN is one of the main genes controlling tomato fruit shape and encodes a member of the IQ67-DOMAIN (IQD) family of calmodulin-binding proteins. When SUN expressed at high levels in the fruit, tomato showed an elongated shape (Xiao et al., 2008). More precisely,
SUN controls tomato shape through redistribution of mass that is mediated by increased cell division in the longitudinal direction and decreased cell division in the transverse direction of the fruit (Wu et al., 2011, 2015). The cucumber CsSUN gene is also involved in the regulation of cucumber spherical fruit development, and the round-fruited WI7239 had a 161-bp deletion in the first exon of CsSUN. The expression of CsSUN in round-fruited WI7239 was significantly lower than that in long-fruited WI7238 (Pan et al., 2017). Although SUN has some effect on the fruit shape of tomato and cucumber, SUN affects the length of tomato and changes the width of cucumber fruits. It is necessary to understand the specific mechanism of SUN in different crops. Thus, although the genes regulating quality traits are conserved in different vegetables, their mechanisms of action remain to be further confirmed.

Constituting a common factor in vegetable quality regulation, phytohormones have diverse effects on vegetable quality. The same hormones can regulate the same phenotypes in different species, but the mechanisms are not consistent; for example, auxin can influence vegetable leaf or fruit size. CsFUL1 inhibited the expression of the auxin transporters PIN1 and PIN7, resulting in a decrease in auxin accumulation in fruit, thereby affecting the fruit length of cucumber (Zhao et al., 2019). BrANT responds to auxin and regulates downstream gene expression of organogenesis and cell proliferation, indicating that ANT promotes leaf growth by regulating cell division (Ding et al., 2018). These observations suggest that auxin controls many aspects of vegetable organ development in different ways (Pattison et al., 2014). Additionally, the same quality traits of vegetables may be affected by different phytohormones. Taking tomato firmness as an example, Moneymaker (MM) tomato has a higher compression resistance than Solanum lycopersicum var. cerasiforme LA1310 (CC). Compared with the fruits of the near-isogenic line with the CC qFIRM SKIN 1 (qFIS1) allele (NIL-FIS1 ${ }^{C C}$ ) Li et al. found that bioactive GAs, including GA1, GA3, and GA7, were dramatically increased, whereas the metabolic products of GA2-oxidases, including GA8 and GA34, were decreased in the fruits of the near-isogenic line with the MM qFIS1 allele (NIL-FIS1 ${ }^{M M}$ ) (Li et al., 2020). By spraying exogenous GA3 on NIL-FIS1 ${ }^{C C}$ mature green fruits, researchers found significantly increased compression resistance in treated fruits compared to untreated controls, indicating that GA levels contribute to higher fruit firmness ( $\mathrm{Li}$ et al., 2020). Moreover, researchers treated wild type tomato fruit with exogenous $\mathrm{ABA}$ and found that fruit firmness decreased, and the suppression of 9-CIS-EPOXYCAROTENOID DIOXYGENASE (SlNCED1), which encodes a key enzyme in ABA biosynthesis, significantly induced tomato fruit firmness (Sun et al., 2012). GA and ABA can both affect tomato firmness, but the specific mechanism of action and the connection between the two require further analysis. Furthermore, there is extensive crosstalk between different phytohormones that control growth and development, such as auxin and GA. AUXIN RESPONSE FACTORS (ARFs) are transcription factors that respond to auxin signals and activate or repress downstream gene expression, thus delivering the signal for the regulation of a set of genes (Roosjen et al., 2018). As critical transcriptional downstream 


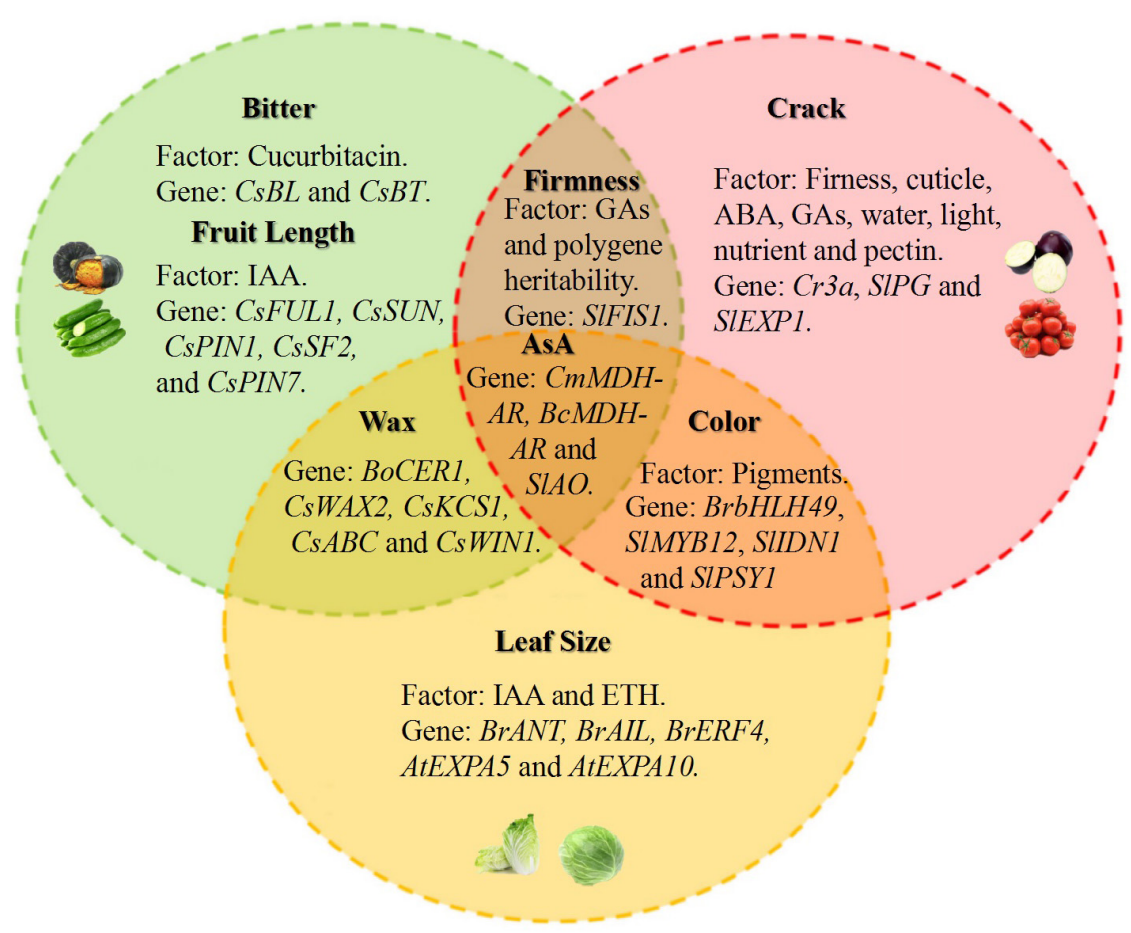

FIGURE 2 | Overview of the factors and genes related to vegetable quality, taking Brassicaceae, Solanaceae and Cucurbitaceae as examples. Phytohormones represent the main factor that can influence fruit length (Cucurbitaceae), leaf size (Brassicaceae), firmness (Solanaceae) and cracking (Solanaceae). Cucurbitacin is a unique substance of cucumbers that affects bitterness. Genes regulate different quality characteristics of vegetables, such as fruit length in cucumber (CsFUL1, CsSUN, CsPIN1, CsPIN7 and CsSF2), cracks in tomato (Cr3a, SIPG and SIEXP1) and leaf size in Chinese cabbage (BrANT, BrAIL and BrERF4). Some homologous genes such as MDHAR also play similar roles in vegetable quality, which affects the content of AsA in non-heading Chinese cabbage and melon.

targets of ARF2, CARBON-METABOLISM INVOLVED (GNC) and GNC-LIKE (GNL) are involved in plant greening, flowering time, and senescence (Richter et al., 2013). It has been reported that the constitutive activation of GA signaling is sufficient to suppress arf 2 mutant phenotypes, causing increased chlorophyll accumulation and delayed senescence through repression of GNC and GNL (Richter et al., 2013). These and other aspects of different pathways suggest complex crosstalk in multiple phytohormone signals, reflecting their pleiotropic effects on vegetable growth and ripening. Finally, phytohormones act as common factors regulating vegetable quality, and deepening the mechanistic understanding of molecular events related to phytohormones will help to elucidate the regulatory networks that affect vegetable quality.

\section{GENETIC MANIPULATION APPLIED IN VEGETABLE QUALITY}

Many researchers have identified the key genes that affect vegetable qualities. For example, Wiesner et al. (2014) identified genes coding for polypeptide four of the cytochrome P450 (CYP) monooxygenase subfamily CYP81F and examined their metabolic roles in indole glucosinolate biosynthesis in Brassica rapa ssp. chinensis by microarray. Li et al. (2016) found that exogenous auxin alters the expression patterns of ethylene and auxin signaling-related genes that are induced or repressed in the normal ripening process by Illumina RNA sequencing. Kompetitive allele-specific PCR (KASP) is a proprietary technology of LGC genomics that can distinguish alleles at variant loci (Semagn et al., 2014; Steele et al., 2018). Paudel et al. (2019) used the four loci to facilitate marker-assisted selection (MAS) for watermelon seed coat color. The results of these studies can be applied to actual production processes to improve vegetable quality. With the development of molecular biology technology, the regulation of vegetable quality is not confined to traditional methods, such as grafting techniques and the application of exogenous fertilizers, but regulation at the molecular level is becoming increasingly common.

DNA molecular marker technologies are marker techniques based on nucleotide differences between individuals. This refers to genetic markers based on DNA. In other words, direct response to genetic material variation at the DNA level may accurately reveal interspecific and intraspecific differences (Vieira et al., 2007; Alim et al., 2011; Ferguson et al., 2012; Xu et al., 2019; El-Mansy et al., 2021).

DNA molecular markers are widely used in vegetable breeding research, including the construction of genetic maps to facilitate the selection of breeding parents, the stable and objective analysis of genetic relationships and plant origin and evolution, and the mapping of agronomic trait genes (Table 1). Restriction fragment 
TABLE 1 | Different types of molecular markers.

\begin{tabular}{|c|c|c|}
\hline Type & Molecular markers & References \\
\hline Molecular hybridization & RFLP & Gebhardt et al., 1991; Sakamoto et al., 2000 \\
\hline PCR & SSR SNP & $\begin{array}{l}\text { Shirasawa et al., 2010; Wang et al., 2012; Gharsallah et al., 2016; Ohyama et al., 2017; } \\
\text { Paudel et al., 2019; Zhang et al., 2020a }\end{array}$ \\
\hline PCR and Restriction Enzyme Digestion Technology & AFLP & Xu et al., 2014 \\
\hline
\end{tabular}

TABLE 2 | Application of transgenic and genome editing technology in vegetables.

\begin{tabular}{|c|c|c|c|c|}
\hline Type & Method & Gene & Quality & Challenges \\
\hline \multirow[t]{2}{*}{ Transgenic technology } & RNAi & SIABCG36 SIABCG42 & Tomato has a thinner stratum corneum & $\begin{array}{l}\text { The safety of genetically modified vegetables is still } \\
\text { unclear }\end{array}$ \\
\hline & VIGS & CaCCS CaPSY CaLCYB CaCRTZ & Pepper fruits turn orange or yellow & \\
\hline \multirow[t]{2}{*}{ Genome editing technology } & CRISPR & SIFIS1 & Increase tomato firmness & Traits do not coexist with others \\
\hline & & CsSF2 & Shoot cucumber fruit & The serious growth inhibition of homozygous plants \\
\hline
\end{tabular}

length polymorphism (RFLP) is the earliest DNA molecular marker technology. By mapping chromosome-specific tomato RFLP markers in potato and conversely mapping potato markers in tomato, the different potato and tomato RFLP maps were aligned, and the similarity of the potato and tomato genomes was confirmed (Gebhardt et al., 1991). RFLP has also been used for the identification of S-haplotypes of breeding lines in broccoli and cabbage (B. oleracea L.) and in purity tests of $\mathrm{F}_{1}$ hybrid seeds (Sakamoto et al., 2000). Simple sequence repeat (SSR) markers have been widely used to obtain new germplasm in recent years. When 32 SSR pairs of primers derived from the A. thaliana chloroplast genome and another 21 SSR primers from the $B$. napus mitochondrial genome sequences were compared, six types of cabbage cytoplasmic male sterility (CMS) were found, namely, NigCMS, OguCMSR (1), OguCMSR (2), OguCMSR (3), OguCMSHY, and PolCMS (Wang et al., 2012). Additionally, Gharsallah et al. (2016) genotyped cultivars using nineteen polymorphic SSRs out of twenty-five tested to produce a total of seventy alleles with an average of 3.68 alleles per locus and polymorphism information content (PIC) values ranging from 0.22 to 0.82 in saline tolerant, mildly tolerant and saline sensitive tomatoes, so SSR marker-genotypes can be used to find potential salt tolerance sources in tomato. Furthermore, the single nucleotide polymorphism (SNP) markers screened in tomato cultivar lines can be used to estimate the transferability of these SNPs to other breeding materials (Shirasawa et al., 2010). A core set of twenty-four SNPs can distinguish 99\% of the two hundred and sixty-one cucumber varieties (Zhang et al., 2020a). These methods can be used comprehensively. For example, amplified fragment length polymorphism (AFLP) and SSR techniques combined with bulk segregant analysis (BSA) can be used to map the RESTORER GENE (BrRFP) in heading Chinese cabbage using the $\mathrm{F}_{2}$ segregating population developed by crossing the polima (pol)-like CMS line 06J45 and the restorer line 01S325 (Xu et al., 2014). Ohyama et al. (2017) identified thirteen important agronomic quantitative trait loci (QTLs) in tomato by SSR molecular markers. Xu et al. (2019) developed thirty-five informative InDel markers that were successfully used to analyze the genetic diversity of thirty-six cabbage germplasms, providing molecular marker data for genetic mapping and germplasm identification and promoting genetic improvement in cabbage breeding.

\section{Transgenic Technology to Regulate the Quality of Vegetables}

Transgenic technology involves the use of modern biotechnology to artificially separate, recombine, introduce, and integrate required target genes into the genome of organisms, thereby improving the original traits or providing new desirable traits (Kumar et al., 2020). Given that the essence of transgenic technology and traditional technology is genetic improvement through the acquisition of excellent genes, the close combination of transgenic technology and conventional breeding techniques can enable breeding of new varieties with multiresistance, high quality, high yield and high efficiency. This approach can greatly improve the efficiency of variety development, reduce the input of pesticides and fertilizers, and enable great potential in alleviating resource constraints, ensuring food safety, protecting the ecological environment and expanding agricultural functions (Ndimba et al., 2017).

Transgenic experiments play an important role in the verification of gene function (Table 2). The tomato genes ATPBINDING CASSETTE TRANSPORTER G 36 (SlABCG36) and $S l A B C G 42$, which encode proteins that are highly homologous to $A t A B C G 32$, can be downregulated using RNAi techniques, resulting in the deposition of the stratum corneum in the tomato fruit and the formation of a thinner stratum corneum; ABCG transporter protein affects the transport of keratin precursors (Elejalde-Palmett et al., 2021). Zhang et al. (2020b) used A. thaliana as a material and overexpressed AtMYB49 to improve the ability of plants to resist oxidative stress. Arce-Rodriguez and Ochoa-Alejo designed a virus-induced gene silencing (VIGS) system for Capsicum, providing a new means for the study of gene function in this genus (ArceRodriguez and Ochoa-Alejo, 2020). The pepper color genes CAPSANTHIN/CAPSORUBIN SYNTHASE (CCS), PHYTOENE SYNTHASE (PSY), LYCOPENE-BETA-CYCLASE (LCYB), and BETA-CAROTENE HYDROXYLASE (CRTZ) were silenced separately through VIGS technology, and pepper fruits from red 
fruit cultivars turned orange or yellow. Moreover, these four genes were silenced simultaneously; the fruits did not show the normal red color ation (Tian et al., 2014). Recently, researchers applied VIGS of pepper genes via a pTRV2-GFP-CaPDS vector, which can visualize TRV spread and monitor VIGS efficiency, thereby enriching the research methods for vegetable germplasm resources (Zhou et al., 2021).

\section{Gene Editing Technology to Regulate the Quality of Vegetables}

Gene editing, also known as genome editing or genome engineering, is a relatively accurate genetic engineering technology or process that can modify specific target genes in the genome of organisms (Schindele and Puchta, 2020). Clustered regularly interspaced short palindromic repeats/Cas (CRISPR/Cas) technology is the third generation of genome editing technology developed in recent years. It is a means to study gene function and improve crop yield. Gene editing shows great potential in gene research and genetic improvement because it can efficiently edit the targeted genome (Li et al., 2021).

At present, CRISPR technology has been applied to the targeted editing of genomes of various organisms (Table 2). Li et al. (2020) used CRISPR/Cas9 technology to edit FIS1 to verify its effect on tomato firmness (Li et al., 2020). SHORT-FRUIT 2 (SF2) encodes histone deacetylase proteins, which participate in diverse and tissue-specific developmental processes by forming various corepressor complexes with different regulatory subunits. Researchers knocked out the SF2 gene by CRISPR/Cas9 and proved that SF2 controls fruit cell proliferation by targeting the biosynthesis and metabolism of cytokinin and polyamines (Zhang et al., 2020c).

\section{PERSPECTIVES}

Currently, there are new demands for vegetable quality in terms of diversity and nutritional health. Improving vegetable quality is an important topic in contemporary vegetable research. Scientists have conducted in-depth research on the molecular development, regulatory mechanisms and biosynthesis of vegetable quality traits. Studies have mainly included the identification of candidate genes, and their loci, which are responsible for fruit quality traits of different varieties of vegetables, as well as the physiological and metabolic pathways that directly or indirectly affect fruit quality traits. In addition, the establishment of efficient genetic transformation methods and the use of gene-editing technology help verify the function of these determinants or regulators. These applications for improving quality attributes make sense when traditional breeding is difficult because of the reproductive isolation between species.

Studies have shown that molecular breeding combined with genome editing technology is growing rapidly, and that this approach can shorten the breeding cycle and greatly improve breeding efficiency, which has become a new direction in vegetable breeding (Ueta et al., 2017). Genome editing has been generally applied in horticulture, and gene edited crops mainly include Solanum lycopersicum, Solanum pimpinellifolium,
Solanum tuberosum, Brassica oleracea, Brassica napus, Brassica carinata, Lettuce sativa, Cucumis sativus, Camelina sativa, Daucus carota, etc. (Xu et al., 2019). Through the application of genome editing technology, new germplasms have been created, such as lettuce with high AsA and strawberry with different sugar contents, and de novo domestication of tomato was realized (Li et al., 2018; Zhang et al., 2018; Xing et al., 2020). However, gene manipulation technologies still face challenges in improving vegetable quality. However, whether or not geneedited vegetables should be regulated as transgenic vegetables has aroused international controversy (Hashimoto et al., 1999; Friedrichs et al., 2019). Thus, gene-edited vegetables are in urgent need of policy support to promote the industrialization of new technologies and products. On the other hand, the precise regulatory mechanisms of complex vegetable traits still need to be further explored. Important agronomic traits might be regulated by multiple gene loci, and one gene may be involved in multiple agronomic traits. For example, SF2, which encodes histone deacetylase protein, not only affects fruit quality but also participates in the normal growth of plants. The cucumber $s f 2$ knockout mutant exhibits severely hindered growth and cannot develop further. The application of CRISPR technology can only be used to analyze the functional mechanism by which CsSF2 regulates cucumber fruit length and cannot be applied to the actual production process (Zhang et al., 2020c). Therefore, one of the biggest challenges facing future gene manipulation technologies is to identify precise trait regulatory networks and disrupt the unwanted linkages between different traits.

Furthermore, the development of genomics, molecular biology, imaging, remote sensing informatics, and big data technology will promote the development of breeding science (Mahlein et al., 2012; Boukar et al., 2019; Walter et al., 2019; Zhao et al., 2019). In particular, the application of big data technology in gene breeding plays a huge role in screening for functional variants, since it improves the efficiency and accuracy of variant detection. The target of genetic variation detection in plants has shifted from single SNP to structural variation and insertion or deletion allelic variation though big data technology (Wong et al., 2019). In summary, although challenges remain, the application of genetic manipulation in horticultural crop species improvement will further create and enhance vegetable quality through the inclusion of desirable traits.

\section{AUTHOR CONTRIBUTIONS}

LG and NH analyzed the gene manipulation effects on the quality of vegetables. TW and JC conceived the original idea for the review. All authors wrote the manuscript.

\section{FUNDING}

This study was supported by the National Key Research and Development Program of China (2018YFD1000800), the National Natural Science Foundation of China (31972429, 31972407, and 32011540003), and the Hunan Provincial Natural Science Foundation of China (2020JJ4363 and 2021JJ10032). 


\section{REFERENCES}

Adato, A., Mandel, T., Mintz-Oron, S., Venger, I., Levy, D., Yativ, M., et al. (2009). Fruit-surface flavonoid accumulation in tomato is controlled by a SIMYB12-regulated transcriptional network. PLoS Genet. 5:e1000777. doi: 10. 1371/journal.pgen. 1000777

Alim, M. A., Sun, D. X., Zhang, Y., and Faruque, M. O. (2011). Genetic markers and their application in buffalo production. J. Anim. Vet. Adv. 10, 1789-1800. doi: 10.3923/javaa.2011.1789.1800

Amagai, Y., Lu, N., Hayashi, E., Takagaki, M., Kikuchi, M., Ibaraki, Y., et al. (2021). External green light as a new tool to change colors and nutritional components of inner leaves of head cabbages. J. Food Meas. 16, 269-280. doi: 10.1007/s11694-021-01150-y

Anderson, G. H. (1995). Sugars, sweetness, and food intake. Am. J. Clin. Nutr. 62(Suppl. 1), 195S-201S. doi: 10.1093/ajcn/62.1.195S

Arce-Rodriguez, M. L., and Ochoa-Alejo, N. (2020). Virus-induced gene silencing (VIGS) in chili pepper (Capsicum spp.). Methods Mol. Biol. 2172, 27-38. doi: 10.1007/978-1-0716-0751-0_3

Aung, M. M., and Chang, Y. S. (2014). Traceability in a food supply chain: safety and quality perspectives. Food Control 39, 172-184. doi: 10.1016/j.foodcont. 2013.11.007

Ballester, A. R., Molthoff, J., de Vos, R., Hekkert, B. T. L., Orzaez, D., FernandezMoreno, J. P., et al. (2010). Biochemical and molecular analysis of pink tomatoes: deregulated expression of the gene encoding transcription factor S1MYB12 leads to pink tomato fruit color. Plant Physiol. 152, 71-84. doi: 10.1104/pp.109.147322

Bargel, H., and Neinhuis, C. (2005). Tomato (Lycopersicon esculentum Mill.) fruit growth and ripening as related to the biomechanical properties of fruit skin and isolated cuticle. J. Exp. Bot. 56, 1049-1060. doi: 10.1093/jxb/eri098

Beckles, D. M. (2012). Factors affecting the postharvest soluble solids and sugar content of tomato (Solanum lycopersicum L.) fruit. Postharvest Biol. Technol. 63, 129-140. doi: 10.1016/j.postharvbio.2011.05.016

Bort, A., Sanchez, B. G., Spinola, E., Mateos-Gomez, P. A., Rodriguez-Henche, N., and Diaz-Laviada, I. (2019). The red pepper's spicy ingredient capsaicin activates AMPK in HepG2 cells through CaMKK beta. PLoS One 14:e211420. doi: 10.1371/journal.pone.0211420

Boukar, O., Belko, N., Chamarthi, S., Togola, A., Batieno, J., Owusu, E., et al. (2019). Cowpea (Vigna unguiculata): genetics, genomics and breeding. Plant Breed. 138, 415-424. doi: 10.1111/pbr.12589

Brashlyanova, B., Zsivanovits, G., and Ganeva, D. (2014). Texture quality of tomatoes as affected by different storage temperatures and growth habit. Emir. J. Food Agric. 26, 750-756. doi: 10.9755/ejfa.v26i9.17484

Broun, P., Poindexter, P., Osborne, E., Jiang, C.-Z., and Riechmann, J. L. (2004). WIN1, a transcriptional activator of epidermal wax accumulation in Arabidopsis. Proc. Natl. Acad. Sci. U.S.A. 101, 4706-4711. doi: 10.1073/pnas. 0305574101

Buscher, R. H., and Buscher, R. W. (2001). Production and stability of (E, Z)-2,6nonadienal, the major flavor volatile of cucumbers. J. Food Sci. 66, 357-361. doi: 10.1111/j.1365-2621.2001.tb11346.x

Buzigi, E., Pillay, K., and Siwela, M. (2021). Potential of pumpkin to combat vitamin A deficiency during complementary feeding in low and middle income countries: variety, provitamin A carotenoid content and retention, and dietary reference intakes. Crit. Rev. Food Sci. Nutr. 8, 1-10. doi: 10.1080/10408398.2021. 1896472

Cao, W. X., Dong, X., Ji, J. L., Yang, L. M., Fang, Z. Y., Zhuang, M., et al. (2021). BoCER1 is essential for the synthesis of cuticular wax in cabbage (Brassica oleracea L. var. capitata). Sci. Hortic. 277:109801. doi: 10.1016/j.scienta.2020. 109801

Chapman, N. H., Bonnet, J., Grivet, L., Lynn, J., Graham, N., Smith, R., et al. (2012). High-resolution mapping of a fruit firmness-related quantitative trait locus in tomato reveals epistatic interactions associated with a complex combinatorial locus. Plant Physiol. 159, 1644-1657. doi: 10.1104/pp.112.200634

Chattopadhyay, T., Hazra, P., Akhtar, S., Maurya, D., Mukherjee, A., and Roy, S. (2021). Skin colour, carotenogenesis and chlorophyll degradation mutant alleles: genetic orchestration behind the fruit colour variation in tomato. Plant Cell Rep. 40, 767-782. doi: 10.1007/s00299-020-02650-9

Chatzopoulou, F., Sanmartin, M., Mellidou, I., Pateraki, I., Koukounaras, A., Tanou, G., et al. (2020). Silencing of ascorbate oxidase results in reduced growth, altered ascorbic acid levels and ripening pattern in melon fruit. Plant Physiol. Biochem. 156, 291-303. doi: 10.1016/j.plaphy.2020.08.040

Chen, L. L., Li, W. Z., Li, Y. P., Feng, X. C., Du, K. Y., Wang, G., et al. (2019). Identified trans-splicing of YELLOW-FRUITED TOMATO 2 encoding the PHYTOENE SYNTHASE 1 protein alters fruit color by map-based cloning, functional complementation and RACE. Plant Mol. Biol. 100, 647-658. doi: 10.1007/s11103-019-00886-y

Cheng, Y., Wang, Q., Ban, Q. Y., Geng, J. F., Zhang, X. W., Yi, Y., et al. (2009). Unconditional and conditional quantitative trait loci mapping for plant height in nonheading Chinese cabbage. Hortscience 44, 268-273. doi: 10.21273/hortsci. 44.2.268

Cox, M. C. H., Millenaar, F. F., Van Berkel, Y. E. M. J., Peeters, A. J. M., and Voesenek, L. A. C. J. (2003). Plant movement. Submergence-induced petiole elongation in Rumex palustris depends on hyponastic growth. Plant Physiol. 132, 282-291. doi: 10.1104/pp.102.014548

de Almeida, A. B., de Lima, T. M., de Oliveira, J. G., Santana, R. V., Lima, D. S., Moreira, E. A., et al. (2019). Relation between physicochemical characteristics and sensory profiles of cooked pumpkin varieties. Emir. J. Food Agric. 31, 697-707. doi: 10.9755/ejfa.2019.v31.i9.2007

Ding, Q., Cui, B., Li, J. J., Li, H. Y., Zhang, Y. H., Lv, X. H., et al. (2018). Ectopic expression of a Brassica rapa AINTEGUMENTA gene (BrANT-1) increases organ size and stomatal density in Arabidopsis. Sci. Rep. 8:10528. doi: 10.1038/ s41598-018-28606-4

Ding, X. T., Yu, L. Y., Jiang, Y. P., Yang, S. J., He, L. Z., Zhou, Q., et al. (2020). Changes in leaf length, width, area, and photosynthesis of fruit cucumber in a greenhouse production system. Hortscience 55, 995-999. doi: 10.21273/ hortsci14637-19

Dou, J. L., Zhao, S. J., Lu, X. Q., He, N., Zhang, L., Ali, A., et al. (2018). Genetic mapping reveals a candidate gene (ClFS1) for fruit shape in watermelon (Citrullus lanatus L.). Theor. Appl. Genet. 131, 947-958. doi: 10.1007/s00122018-3050-5

El-Mansy, A. B., Abd El-Moneim, D., Alshamrani, S. M., Alsafhi, F. A., Abdein, M. A., and Ibrahim, A. A. (2021). Genetic diversity analysis of tomato (Solanum lycopersicum L.) with morphological, cytological, and molecular markers under heat stress. Horticulturae 7:65. doi: 10.3390/horticulturae7040065

Elejalde-Palmett, C., San Segundo, I. M., Garroum, I., Charrier, L., De Bellis, D., Mucciolo, A., et al. (2021). ABCG transporters export cutin precursors for the formation of the plant cuticle. Curr. Biol. 31, 2111-2123.e9. doi: 10.1016/j.cub. 2021.02.056

Eltelib, H. A., Badejo, A. A., Fujikawa, Y., and Esaka, M. (2011). Gene expression of monodehydroascorbate reductase and dehydroascorbate reductase during fruit ripening and in response to environmental stresses in acerola (Malpighia glabra). J. Plant Physiol. 168, 619-627. doi: 10.1016/j.jplph.2010. 09.003

Ferguson, M., Rabbi, I., Kim, D. J., Gedil, M., Lopez-Lavalle, L. A. B., and Okogbenin, E. (2012). Molecular markers and their application to cassava breeding: past, present and future. Trop. Plant Biol. 5, 95-109. doi: 10.1007/ s12042-011-9087-0

Friedrichs, S., Takasu, Y., Kearns, P., Dagallier, B., Oshima, R., Schofield, J., et al. (2019). Meeting report of the OECD conference on "Genome editing: applications in agriculture-implications for health, environment and regulation”. Transgenic Res. 28, 419-463. doi: 10.1007/s11248-019-00154-1

Gao, L., Zhao, S. J., Lu, X. Q., He, N., Zhu, H. J., Dou, J. L., et al. (2018). Comparative transcriptome analysis reveals key genes potentially related to soluble sugar and organic acid accumulation in watermelon. PLoS One 13:e0190096. doi: 10.1371/journal.pone.0190096

Ge, H. L., Liu, Z. H., and Zhang, F. L. (2017). Effect of Rhodopseudomonas palustris G5 on seedling growth and some physiological and biochemical characteristics of cucumber under cadmium stress. Emir. J. Food Agric. 29, 816-821. doi: 10.9755/ejfa.2017.v29.i11.1327

Gebhardt, C., Ritter, E., Barone, A., Debener, T., Walkemeier, B., Schachtschabel, U., et al. (1991). RFLP maps of potato and their alignment with the homoeologous tomato genome. Theor. Appl. Genet. 83, 49-57. doi: 10.1007/ bf00229225

Gebretsadik, K., Qiu, X. Y., Dong, S. Y., Miao, H., and Bo, K. L. (2021). Molecular research progress and improvement approach of fruit quality traits in cucumber. Theor. Appl. Genet. 134, 3535-3552. doi: 10.1007/s00122-02103895-y 
Gharsallah, C., Ben Abdelkrim, A., Fakhfakh, H., Salhi-Hannachi, A., and Gorsane, F. (2016). SSR marker-assisted screening of commercial tomato genotypes under salt stress. Breed. Sci. 66, 823-830. doi: 10.1270/jsbbs.16112

Hashimoto, W., Momma, K., Katsube, T., Ohkawa, Y., Ishige, T., Kito, M., et al. (1999). Safety assessment of genetically engineered potatoes with designed soybean glycinin: compositional analyses of the potato tubers and digestibility of the newly expressed protein in transgenic potatoes. J. Sci. Food Agric. 79, 1607-1612. doi: 10.1002/(sici)1097-0010(199909)79:12<1607::aid-jsfa408<3.0. $\mathrm{co} ; 2-\mathrm{t}$

Hongsoongnern, P., and Chambers, E. (2008). A lexicon for texture and flavor characteristics of fresh and processed tomatoes. J. Sens. Stud. 23, 583-599. doi: 10.1111/j.1745-459X.2008.00174.X

Hu, D. L., Richards, P., and Alexeev, A. (2011). The growth of giant pumpkins: how extreme weight influences shape. Int. J. Nonlin. Mech. 46, 637-647. doi: 10.1016/j.ijnonlinmec.2010.12.013

Hwang, I., Kim, Y., Han, J., and Nou, I. S. (2016). Orange color is associated with CYC-B expression in tomato fleshy fruit. Mol. Breed. 36, 1-10. doi: 10.1007/ s11032-016-0465-z

Jiang, F. L., Lopez, A., Jeon, S., de Freitas, S. T., Yu, Q. H., Wu, Z., et al. (2019). Disassembly of the fruit cell wall by the ripening-associated polygalacturonase and expansin influences tomato cracking. Hortic. Res. 6:17. doi: 10.1038/ s41438-018-0105-3

Jiang, L., Yan, S. S., Yang, W. C., Li, Y. Q., Xia, M. X., Chen, Z. J., et al. (2015). Transcriptomic analysis reveals the roles of microtubule-related genes and transcription factors in fruit length regulation in cucumber (Cucumis sativus L.). Sci. Rep. 5:8031. doi: 10.1038/srep08031

Jin, X., Oliviero, T., van der Sman, R. G. M., Verkerk, R., Dekker, M., and van Boxtel, A. J. B. (2014). Impact of different drying trajectories on degradation of nutritional compounds in broccoli (Brassica oleracea var. italica). LWT Food Sci. Technol. 59, 189-195. doi: 10.1016/j.lwt.2014.05.031

Karamat, U., Sun, X. X., Li, N., and Zhao, J. J. (2021). Genetic regulators of leaf size in Brassica crops. Hortic. Res. 8:91. doi: 10.1038/s41438-021-00526-X

Khadivi-Khub, A. (2015). Physiological and genetic factors influencing fruit cracking. Acta Physiol. Plant. 37:1718. doi: 10.1007/s11738-014-1718-2

Kim, K. D., Suh, J. T., Lee, J. N., Yoo, D. L., Nam, J. H., Sohn, H. B., et al. (2020). Development of evaluation methods and determination of hardness variation with leaf order and tissue type of Kimchi cabbage during summer harvest. Hortic. Environ. Biotechnol. 61, 815-824. doi: 10.1007/s13580-020-0 0266-2

Kim, S., Park, M., Yeom, S. I., Kim, Y. M., Lee, J. M., Lee, H. A., et al. (2014). Genome sequence of the hot pepper provides insights into the evolution of pungency in Capsicum species. Nat. Genet. 46, 270-278. doi: 10.1038/ng.2877

Klucher, K. M., Chow, H., Reiser, L., and Fischer, R. L. (1996). The AINTEGUMENTA gene of Arabidopsis required for ovule and female gametophyte development is related to the floral homeotic gene APETALA2. Plant Cell 8, 137-153. doi: 10.1105/tpc.8.2.137

Koyama, R., Itoh, H., Kimura, S., Morioka, A., and Uno, Y. (2012). Augmentation of antioxidant constituents by drought stress to roots in leafy vegetables. Horttechnology 22, 121-125. doi: 10.21273/horttech.22.1.121

Kumar, K., Gambhir, G., Dass, A., Tripathi, A. K., Singh, A., Jha, A. K., et al. (2020). Genetically modified crops: current status and future prospects. Planta 251:91. doi: 10.1007/s00425-020-03372-8

Laila, R., Robin, A. H. K., Yang, K., Park, J. I., Suh, M. C., Kim, J., et al. (2017). Developmental and genotypic variation in leaf wax content and composition, and in expression of wax biosynthetic genes in Brassica oleracea var. capitata. Front. Plant Sci. 7:1972. doi: 10.3389/fpls.2016.01972

Li, G. H., Chen, H. C., Liu, J. L., Luo, W. L., Xie, D. S., Luo, S. B., et al. (2019). A high-density genetic map developed by specific-locus amplified fragment (SLAF) sequencing and identification of a locus controlling anthocyanin pigmentation in stalk of Zicaitai (Brassica rapa L. ssp. chinensis var. purpurea). BMC Genomics 20:343. doi: 10.1186/s12864-019-5693-2

Li, H., Wu, H., Qi, Q., Li, H. H., Li, Z. F., Chen, S., et al. (2019). Gibberellins play a role in regulating tomato fruit ripening. Plant Cell Physiol. 60, 1619-1629. doi: $10.1093 / \mathrm{pcp} / \mathrm{pcz} 069$

Li, J. Y., Tao, X. Y., Li, L., Mao, L. C., Luo, Z. S., Khan, Z. U., et al. (2016). Comprehensive RNA-Seq analysis on the regulation of tomato ripening by exogenous auxin. PLoS One 11:e0156453. doi: 10.1371/journal.pone.015 6453
Li, R., Sun, S., Wang, H., Wang, K., Yu, H., Zhou, Z., et al. (2020). FIS1 encodes a GA2-oxidase that regulates fruit firmness in tomato. Nat. Commun. 11:5844. doi: 10.1038/s41467-020-19705-w

Li, T. D., Yang, X. P., Yu, Y., Si, X. M., Zhai, X. W., Zhang, H. W., et al. (2018). Domestication of wild tomato is accelerated by genome editing. Nat. Biotechnol. 36, 1160-1163. doi: 10.1038/nbt.4273

Li, Y., Li, W. J., and Li, J. (2021). The CRISPR/Cas9 revolution continues: from base editing to prime editing in plant science. J. Genet. Genomics 48, 661-670. doi: 10.1016/j.jgg.2021.05.001

Liu, J. Y., Shi, M. J., Wang, J., Zhang, B., Li, Y. S., Wang, J., et al. (2020). Comparative transcriptomic analysis of the development of sepal morphology in tomato (Solanum lycopersicum L.). Int. J. Mol. Sci. 21:5914. doi: 10.3390/ ijms21165914

Liu, Y. W., Pu, H. B., and Sun, D. W. (2017). Hyperspectral imaging technique for evaluating food quality and safety during various processes: a review of recent applications. Trends Food Sci. Technol. 69, 25-35. doi: 10.1016/j.tifs.2017.08.013

Ma, X. Q., Ding, Q., Hou, X. L., and You, X. (2021). Analysis of flavonoid metabolites in watercress (Nasturtium officinale $\mathrm{R}$. Br.) and the non-heading Chinese cabbage (Brassica rapa ssp. chinensis cv. Aijiaohuang) using UHPLCESI-MS/MS. Molecules 26:5825. doi: 10.3390/molecules26195825

Mahlein, A. K., Oerke, E. C., Steiner, U., and Dehne, H. W. (2012). Recent advances in sensing plant diseases for precision crop protection. Eur. J. Plant Pathol. 133, 197-209. doi: 10.1007/s10658-011-9878-z

Martinez-Bello, L., Moritz, T., and Lopez-Diaz, I. (2015). Silencing C-19-GA 2oxidases induces parthenocarpic development and inhibits lateral branching in tomato plants. J. Exp. Bot. 66, 5897-5910. doi: 10.1093/jxb/erv300

Mashiane, P., Mashitoa, F. M., Slabbert, R. M., and Sivakumar, D. (2021). Impact of household cooking techniques on colour, antioxidant and sensory properties of African pumpkin and pumpkin leaves. Int. J. Gastron. Food Sci. 23:100307. doi: 10.1016/j.ijgfs.2021.100307

Muller, M., and Munne-Bosch, S. (2015). Ethylene response factors: a key regulatory hub in hormone and stress signaling. Plant Physiol. 169, 32-41. doi: $10.1104 /$ pp.15.00677

Munir, S., Mumtaz, M. A., Ahiakpa, J. K., Liu, G. Z., Chen, W. F., Zhou, G. L., et al. (2020). Genome-wide analysis of Myo-inositol oxygenase gene family in tomato reveals their involvement in ascorbic acid accumulation. BMC Genomics 21:284. doi: 10.1186/s12864-020-6708-8

Nakamura, K., Mori, F., Tanji, K., Miki, Y., Yamada, M., Kakita, A., et al. (2015). Isopentenyl diphosphate isomerase, a cholesterol synthesizing enzyme, is localized in Lewy bodies. Neuropathology 35, 432-440. doi: 10.1111/neup. 12204

Ndimba, R. J., Kruger, J., Mehlo, L., Barnabas, A., Kossmann, J., and Ndimba, B. K. (2017). A comparative study of selected physical and biochemical traits of wildtype and transgenic sorghum to reveal differences relevant to grain quality. Front. Plant Sci. 8:952. doi: 10.3389/fpls.2017.00952

Note-Wilson, S., Azhakanandam, S., and Franks, R. G. (2010). Polar auxin transport together with AINTEGUMENTA and REVOLUTA coordinate early Arabidopsis gynoecium development. Dev. Biol. 346, 181-195. doi: 10.1016/j. ydbio.2010.07.016

Ohyama, A., Shirasawa, K., Matsunaga, H., Negoro, S., Miyatake, K., Yamaguchi, H., et al. (2017). Bayesian QTL mapping using genome-wide SSR markers and segregating population derived from a cross of two commercial F-1 hybrids of tomato. Theor. Appl. Genet. 130, 1601-1616. doi: 10.1007/s00122-017-2913-5

Olfati, J. A., Peyvast, G., Shabani, H., and Nosratie-Rad, Z. (2010). An estimation of individual leaf area in cabbage and broccoli using non-destructive methods. J. Agric. Sci. Technol. 12, 627-632. doi: 10.1111/j.1744-697X.2010.00192.x

Pan, Y. P., Liang, X. J., Gao, M. L., Liu, H. Q., Meng, H. W., Weng, Y. Q., et al. (2017). Round fruit shape in WI7239 cucumber is controlled by two interacting quantitative trait loci with one putatively encoding a tomato SUN homolog. Theor. Appl. Genet. 130, 573-586. doi: 10.1007/s00122-016-2836-6

Park, A. K., Kim, I. S., Do, H., Jeon, B. W., Lee, C. W., Roh, S. J., et al. (2016). Structure and catalytic mechanism of monodehydroascorbate reductase, MDHAR, from Oryza sativa L. japonica. Sci. Rep. 6:33903. doi: 10.1038/ srep33903

Park, J. B., Sendon, P. M., Kwon, S. H., Seo, H. S., Park, S. K., Kim, J. H., et al. (2012). Overexpression of stress-related genes, BrERF4 and AtMYB44, in Arabidopsis thaliana alters cell expansion but not cell proliferation during leaf growth. J. Plant Biol. 55, 406-412. doi: 10.1007/s12374-012-0114-y 
Pattison, R. J., Csukasi, F., and Catala, C. (2014). Mechanisms regulating auxin action during fruit development. Physiol. Plant. 151, 62-72. doi: 10.1111/ppl. 12142

Paudel, L., Clevenger, J., and McGregor, C. (2019). Chromosomal locations and interactions of four loci associated with seed coat color in watermelon. Front. Plant Sci. 10:788. doi: 10.3389/fpls.2019.00788

Ren, J., Duan, W. K., Chen, Z. W., Zhang, S., Song, X. M., Liu, T. K., et al. (2015). Overexpression of the monodehydroascorbate reductase gene from non-heading Chinese cabbage reduces ascorbate level and growth in transgenic tobacco. Plant Mol. Biol. Rep. 33, 881-892. doi: 10.1007/s11105-014-0797-y

Richter, R., Behringer, C., Zourelidou, M., and Schwechheimer, C. (2013). Convergence of auxin and gibberellin signaling on the regulation of the GATA transcription factors GNC and GNL in Arabidopsis thaliana. Proc. Natl. Acad. Sci. U.S.A. 110, 13192-13197. doi: 10.1073/pnas.1304250110

Romero, P., and Rose, J. K. C. (2019). A relationship between tomato fruit softening, cuticle properties and water availability. Food Chem. 295, 300-310. doi: 10.1016/j.foodchem.2019.05.118

Roosjen, M., Paque, S., and Weijers, D. (2018). Auxin response factors: output control in auxin biology. J. Exp. Bot. 69, 179-188. doi: 10.1093/jxb/erx237

Sakamoto, K., Kusaba, M., and Nishio, T. (2000). Single-seed PCR-RFLP analysis for the identification of S haplotypes in commercial F1 hybrid cultivars of broccoli and cabbage. Plant Cell Rep. 19, 400-406. doi: 10.1007/s002990050747

Schindele, P., and Puchta, H. (2020). Engineering CRISPR/LbCas12a for highly efficient, temperature-tolerant plant gene editing. Plant Biotechnol. J. 18, 11181120. doi: $10.1111 /$ pbi.13275

Semagn, K., Babu, R., Hearne, S., and Olsen, M. (2014). Single nucleotide polymorphism genotyping using Kompetitive Allele Specific PCR (KASP): overview of the technology and its application in crop improvement. Mol. Breed. 33, 1-14. doi: 10.1007/s11032-013-9917-X

Shang, Y., Ma, Y. S., Zhou, Y., Zhang, H. M., Duan, L. X., Chen, H. M., et al. (2014). Biosynthesis, regulation, and domestication of bitterness in cucumber. Science 346, 1084-1088. doi: 10.1126/science. 1259215

Shimomura, K., Horie, H., Sugiyama, M., Kawazu, Y., and Yoshioka, Y. (2016). Quantitative evaluation of cucumber fruit texture and shape traits reveals extensive diversity and differentiation. Sci. Hortic. 199, 133-141. doi: 10.1016/j. scienta.2015.12.033

Shin, J. H., Yoo, H. J., Yeam, I., and Lee, J. M. (2019). Distinguishing two genetic factors that control yellow fruit color in tomato. Hortic. Environ. Biotechnol. 60, 59-67. doi: 10.1007/s13580-018-0093-0

Shirasawa, K., Isobe, S., Hirakawa, H., Asamizu, E., Fukuoka, H., Just, D., et al. (2010). SNP discovery and linkage map construction in cultivated tomato. DNA Res. 17, 381-391. doi: 10.1093/dnares/dsq024

Shu-juan, Z., Fang-fang, Y., Zhao-jun, Y., Ming-ke, Z., and Mai-xia, H. (2016). Cloning and expression analysis of $B r L O M 2$, a gene involved in lobed leaf development in pak choi. Acta Hortic. Sin. 43, 2029-2038. doi: 10.16420/j.issn. 0513-353x.2016-0252

Steele, K. A., Quinton-Tulloch, M. J., Amgai, R. B., Dhakal, R., Khatiwada, S. P., Vyas, D., et al. (2018). Accelerating public sector rice breeding with high-density KASP markers derived from whole genome sequencing of indica rice. Mol. Breed. 38:38. doi: 10.1007/s11032-018-0777-2

Sun, L., Sun, Y. F., Zhang, M., Wang, L., Ren, J., Cui, M. M., et al. (2012). Suppression of 9-cis-epoxycarotenoid dioxygenase, which encodes a key enzyme in abscisic acid biosynthesis, alters fruit texture in transgenic tomato. Plant Physiol. 158, 283-298. doi: 10.1104/pp.111.186866

Tian, S. L., Li, L., Chai, W. G., Shah, S. N. M., and Gong, Z. H. (2014). Effects of silencing key genes in the capsanthin biosynthetic pathway on fruit color of detached pepper fruits. BMC Plant Biol. 14:314. doi: 10.1186/s12870-0140314-3

Ueta, R., Abe, C., Watanabe, T., Sugano, S. S., Ishihara, R., Ezura, H., et al. (2017). Rapid breeding of parthenocarpic tomato plants using CRISPR/Cas9. Sci. Rep. 7:507. doi: 10.1038/s41598-017-00501-4

Veerappan, K., Jung, H. J., Hwang, I., Kho, K. H., Chung, M. Y., and Nou, I. S. (2016). Sequence variation in SIMYB12 is associated with fruit peel color in pink tomato cultivars. Hortic. Environ. Biotechnol. 57, 274-279. doi: 10.1007/ s13580-016-0041-9

Vieira, E. A., de Carvalho, F. I. F., Bertan, I., Kopp, M. M., Zimmer, P. D., Benin, G., et al. (2007). Association between genetic distances in wheat (Triticum aestivum
L.) as estimated by AFLP and morphological markers. Genet. Mol. Biol. 30, 392-399. doi: 10.1590/s1415-47572007000300016

Walter, J., Edwards, J., Cai, J. H., McDonald, G., Miklavcic, S. J., and Kuchel, H. (2019). High-throughput field imaging and basic image analysis in a wheat breeding programme. Front. Plant Sci. 10:449. doi: 10.3389/fpls.2019.00449

Wang, C. J., Wang, Y. L., Wang, M. M., Han, H. Y., Luo, Y. S., Ding, W. Q., et al. (2020). Soluble sugars accumulation and related gene expression during fruit development in Cucurbita maxima Duchesne. Sci. Hortic. 272:109520. doi: 10.1016/j.scienta.2020.109520

Wang, L., Wen, M., Chen, F. P., Luo, Z., Yin, J., Chen, Y. L., et al. (2020). High oxygen atmospheric packaging (HOAP) reduces $\mathrm{H}_{2} \mathrm{O}_{2}$ production by regulating the accumulation of oxidative stress-related proteins in Chinese flowering cabbage. Postharvest Biol. Technol. 165:111183. doi: 10.1016/j. postharvbio.2020.111183

Wang, Q. B., Zhang, Y. Y., Fang, Z. Y., Liu, Y. M., Yang, L. M., and Zhuang, M. (2012). Chloroplast and mitochondrial SSR help to distinguish allo-cytoplasmic male sterile types in cabbage (Brassica oleracea L. var. capitata). Mol. Breed. 30, 709-716. doi: 10.1007/s11032-011-9656-9

Wang, W. J., Liu, X. W., Gai, X. S., Ren, J. J., Liu, X. F., Cai, Y. L., et al. (2015). Cucumis sativus L. WAX2 plays a pivotal role in wax biosynthesis, influencing pollen fertility and plant biotic and abiotic stress responses. Plant Cell Physiol. 56, 1339-1354. doi: 10.1093/pcp/pcv052

Wei, G., Tian, P., Zhang, F. X., Qin, H., Miao, H., Chen, Q. W., et al. (2016). Integrative analyses of nontargeted volatile profiling and transcriptome data provide molecular insight into VOC diversity in cucumber plants (Cucumis sativus). Plant Physiol. 172, 603-618. doi: 10.1104/pp.16.01051

Wiesner, M., Schreiner, M., and Zrenner, R. (2014). Functional identification of genes responsible for the biosynthesis of 1-methoxy-indol-3-ylmethylglucosinolate in Brassica rapa ssp chinensis. BMC Plant Biol. 14:124. doi: 10. 1186/1471-2229-14-124

Wong, K. C., Zhang, J., Yan, S. K., Li, X. T., Lin, Q. Z., Kwong, S., et al. (2019). DNA sequencing technologies: sequencing data protocols and bioinformatics tools. ACM Comput. Surv. 52, 1-30. doi: 10.1145/3340286

Wright, J. M., Carunchia Whetstine, M. E., Miracle, R. E., and Drake, M. (2006). Characterization of a cabbage off-flavor in whey protein isolate. J. Food Sci. 71, C86-C90. doi: 10.1111/j.1365-2621.2006.tb08887.x

Wu, S., Clevenger, J. P., Sun, L., Visa, S., Kamiya, Y., Jikumaru, Y., et al. (2015). The control of tomato fruit elongation orchestrated by sun, ovate and fs 8.1 in a wild relative of tomato. Plant Sci. 238, 95-104. doi: 10.1016/j.plantsci.2015.05.019

Wu, S., Xiao, H., Cabrera, A., Meulia, T., and van der Knaap, E. (2011). SUN regulates vegetative and reproductive organ shape by changing cell division patterns. Plant Physiol. 157, 1175-1186. doi: 10.1104/pp.111.181065

Xiao, H., Jiang, N., Schaffner, E., Stockinger, E. J., and van der Knaap, E. (2008). A retrotransposon-mediated gene duplication underlies morphological variation of tomato fruit. Science 319, 1527-1530. doi: 10.1126/science. 1153040

Xing, S. N., Chen, K. L., Zhu, H. C., Zhang, R., Zhang, H. W., Li, B. B., et al. (2020). Fine-tuning sugar content in strawberry. Genome Biol. 21:230. doi: 10.1186/s13059-020-02146-5

Xu, J. M., Hua, K., and Lang, Z. B. (2019). Genome editing for horticultural crop improvement. Hortic. Res. 6:113. doi: 10.1038/s41438-019-0196-5

Xu, X. Y., Sun, X. L., Zhang, Y., Zhang, L. G., and Fang, Z. Y. (2014). Identification of AFLP and SSR markers linked with the male fertility restorer gene of CMS 06J45 in heading Chinese cabbage (Brassica rapa L. ssp pekinensis). Plant Breed. 133, 615-619. doi: 10.1111/pbr.12200

Xu, Y. Y., Zeng, A. S., Song, L. X., Li, J. Q., and Yan, J. Y. (2019). Comparative transcriptomics analysis uncovers alternative splicing events and molecular markers in cabbage (Brassica oleracea L.). Planta 249, 1599-1615. doi: 10.1007/ s00425-019-03108-3

Xue, L. Z., Sun, M. T., Wu, Z., Yu, L., Yu, Q. H., Tang, Y. P., et al. (2020). LncRNA regulates tomato fruit cracking by coordinating gene expression via a hormoneredox-cell wall network. BMC Plant Biol. 20:162. doi: 10.1186/s12870-02002373-9

Yang, T. X., Deng, L., Zhao, W., Zhang, R. X., Jiang, H. L., Ye, Z. B., et al. (2019). Rapid breeding of pink-fruited tomato hybrids using the CRISPR/Cas9 system. J. Genet. Genomics 46, 505-508. doi: 10.1016/j.jgg.2019.10.002

Yang, Z., Wu, Z., Zhang, C., Hu, E. M., Zhou, R., and Jiang, F. L. (2016). The composition of pericarp, cell aging, and changes in water absorption in two 
tomato genotypes: mechanism, factors, and potential role in fruit cracking. Acta Physiol. Plant. 38:215. doi: 10.1007/s11738-016-2228-1

Yildiz, H., and Baysal, T. (2007). Color and lycopene content of tomato puree affected by electroplasmolysis. Int. J. Food Prop. 10, 489-495. doi: 10.1080/ 10942910600909063

Yoo, H. J., Park, W. J., Lee, G. M., Oh, C. S., Yeam, I., Won, D. C., et al. (2017). Inferring the genetic determinants of fruit colors in tomato by carotenoid profiling. Molecules 22:764. doi: 10.3390/molecules22050764

Yu, Z., Lina, A., Zejun, H., Yongchen, D., Yanmei, G., Junming, L., et al. (2020). Fine mapping of fruit cracking-resistant gene Cr3a in tomato. Acta Hortic. Sin. 47, 275-286. doi: 10.16420/j.issn.0513-353x.2019-0260

Zhang, C., Win, K. T., Kim, Y. C., and Lee, S. (2019). Two types of mutations in the HEUKCHEEM gene functioning in cucumber spine color development can be used as signatures for cucumber domestication. Planta 250, 1491-1504. doi: 10.1007/s00425-019-03244-w

Zhang, H. W., Si, X. M., Ji, X., Fan, R., Liu, J. X., Chen, K. L., et al. (2018). Genome editing of upstream open reading frames enables translational control in plants. Nat. Biotechnol. 36, 894-898. doi: 10.1038/nbt.4202

Zhang, J., Yang, J. J., Yang, Y., Luo, J., Zheng, X. Y., Wen, C. L., et al. (2019). Transcription factor CsWIN1 regulates pericarp wax biosynthesis in cucumber grafted on pumpkin. Front. Plant Sci. 10:1564. doi: 10.3389/fpls.2019. 01564

Zhang, J., Yang, J. J., Zhang, L. K., Luo, J., Zhao, H., Zhang, J. A., et al. (2020a). A new SNP genotyping technology target SNP-seq and its application in genetic analysis of cucumber varieties. Sci. Rep. 10:5623. doi: 10.1038/s41598-02062518-6

Zhang, P., Wang, R. L., Yang, X. P., Ju, Q., Li, W. Q., Lu, S. Y., et al. (2020b). The R2R3-MYB transcription factor AtMYB49 modulates salt tolerance in Arabidopsis by modulating the cuticle formation and antioxidant defence. Plant Cell Environ. 43, 1925-1943. doi: 10.1111/pce.13784

Zhang, Z., Wang, B. W., Wang, S. H., Lin, T., Yang, L., Zhao, Z. L., et al. (2020c). Genome-wide target mapping shows histone deacetylase complexl regulates cell proliferation in cucumber fruit. Plant Physiol. 182, 167-184. doi: 10.1104/ pp. 19.00532

Zhang, J. P., Feng, S. J., Yuan, J., Wang, C., Lu, T., Wang, H. S., et al. (2021). The formation of fruit quality in Cucumis sativus L. Front. Plant Sci. 12:729448. doi: 10.3389/fpls.2021.729448

Zhang, N., Shi, J. W., Zhao, H. Y., and Jiang, J. (2018). Activation of small heat shock protein (SIHSP17.7) gene by cell wall invertase inhibitor (SlCIF1) gene involved in sugar metabolism in tomato. Gene 679, 90-99. doi: 10.1016/j.gene. 2018.08.077
Zhang, Y. Y., Li, H. X., Shu, W. B., Zhang, C. J., and Ye, Z. B. (2011a). RNA interference of a mitochondrial APX gene improves vitamin $\mathrm{C}$ accumulation in tomato fruit. Sci. Hortic. 129, 220-226. doi: 10.1016/j.scienta.2011.03.025

Zhang, Y. Y., Li, H. X., Shu, W. B., Zhang, C. J., Zhang, W., and Ye, Z. B. (2011b). Suppressed expression of ascorbate oxidase gene promotes ascorbic acid accumulation in tomato fruit. Plant Mol. Biol. Rep. 29, 638-645. doi: 10.1007/s11105-010-0271-4

Zhao, C. J., Zhang, Y., Du, J. J., Guo, X. Y., Wen, W. L., Gu, S. H., et al. (2019). Crop phenomics: current status and perspectives. Front. Plant Sci. 10:714. doi: 10.3389/fpls.2019.00714

Zhao, J., Jiang, L., Che, G., Pan, Y., Li, Y., Hou, Y., et al. (2019). A functional allele of CsFUL1 regulates fruit length through repressing CsSUP and inhibiting auxin transport in cucumber. Plant Cell 31, 1289-1307. doi: 10.1105/tpc.18.00905

Zhou, X. H., Liu, S. Y., Liu, Y. P., Liu, J., Yang, Y., Wang, D., et al. (2021) Extensive transcriptome changes underlying the fruit skin colour intensity variation in purple eggplant. Notulae Bot. Horti Agrobot. Cluj Napoca 49:12434. doi: $10.15835 /$ nbha49312434

Zhou, Y. J., Deng, Y. T., Liu, D., Wang, H. Z., Zhang, X., Liu, T. T., et al. (2021) Promoting virus-induced gene silencing of pepper genes by a heterologous viral silencing suppressor. Plant Biotechnol. J. 19, 2398-2400. doi: 10.1111/pbi.13724

Zhu, Z. S., Sun, B. M., Cai, W., Zhou, X., Mao, Y. H., Chen, C. J., et al. (2019). Natural variations in the MYB transcription factor MYB31 determine the evolution of extremely pungent peppers. New Phytol. 223, 922-938. doi: 10. $1111 /$ nph.15853

Conflict of Interest: The authors declare that the research was conducted in the absence of any commercial or financial relationships that could be construed as a potential conflict of interest.

Publisher's Note: All claims expressed in this article are solely those of the authors and do not necessarily represent those of their affiliated organizations, or those of the publisher, the editors and the reviewers. Any product that may be evaluated in this article, or claim that may be made by its manufacturer, is not guaranteed or endorsed by the publisher.

Copyright (c) $2022 \mathrm{Gao}, \mathrm{Hao}, \mathrm{Wu}$ and Cao. This is an open-access article distributed under the terms of the Creative Commons Attribution License (CC BY). The use, distribution or reproduction in other forums is permitted, provided the original author(s) and the copyright owner(s) are credited and that the original publication in this journal is cited, in accordance with accepted academic practice. No use, distribution or reproduction is permitted which does not comply with these terms. 